\title{
Comparison of Complications between Total and Subtotal Thyroidectomy in Simple Multinodular Goitre
}

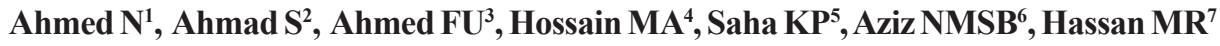

Conflict of Interest: None

Received: 22-08-2017

Accepted: $16-11-2017$

www.banglajol.info/index.php/JSSMC

Key Words:

Simple multinodular goitre, Total thyroidectomy, Subtotal

thyroidectomy, Complications of

thyroid surgery.

\begin{abstract}
:
Background: Multinodular goitre is one of the most common endocrine surgical problems. Because controversy still continues to surround the use of total thyroidectomy for management of simple nodular goitre, the present study was conducted to compare the complications between total and subtotal thyroidectomy for management of simple multinodular goitre.
\end{abstract}

Materials \& methods: The experimental study was conducted in the department of Surgery and ENT, Rajshahi Medical College Hospital over a period of 2 years from July 2011 to June 2013. Of the total 83 simple multinodular goitre patients - 38 were assigned to total and 45 to subtotal thyroidectomy groups. Student's t-test was done to analyze the means of quantitative variables \& Chi-square $\left(\mathrm{X}^{2}\right)$ and Fisher Exact test was applied to analyze categorical variables.

Results: Most (88.9\%) of patients in subtotal thyroidectomy (STT) group and $86.8 \%$ in total thyroidectomy (TT) group did not receive any blood transfusion during operation. Only 1(2.2\%) patient in STT group experienced significant intraoperative haemorrhage. All patients were successfully operated. However, few patients of either group experienced some complications. Tetany was developed in $7.89 \%$ patients of TT and $4.44 \%$ patients of STT group. The other complication was recurrent laryngeal nerve (RLN) palsy (5.3\% in TT and 2.2\% in STT groups). No case of postoperative haemorrhage (haematoma) or wound infection was occured in either group. In TT group 5 (13.16\%) patients and in STT group 4 (8.89\%) patients developed different complications with no significant difference between the groups $(p=0.533)$. The mean postoperative hospital stay was higher in TT group than In STT group (6.21 \pm 0.99 vs. $5.96 \pm$ 0.79 days), though the difference is not statistically significant $(p=0.206)$.

Conclusions: The study shows that total thyroidectomy can be performed without increasing risk of complications and is a better alternative to subtotal thyroidectomy for the treatment of simple multinodular goitre.

[J Shaheed Suhrawardy Med Coll 2017; 9(2): 55-59] DOI: http://dx.doi.org/10.3329/jssmc.v9i2.37263
1. Dr. Nadim Ahmed, Senior Consultant, Department of Surgery, Shaheed Suhrawardy Medical College and Hospital, Dhaka

2. Dr. Sami Ahmad, Associate Professor, Department of Surgery, Shaheed Suhrawardy Medical College and Hospital, Dhaka

3. Dr. Farhad Uddin Ahmed, Junior Consultant, Department of Surgery, Shaheed Suhrawardy Medical College and Hospital, Dhaka

4. Dr. Muhammad Anwar Hossain, Junior Consultant (Surgery), Upazila Health Complex, Keranigonj, Dhaka

5. Dr. Krishna Pada Saha, Junior Consultant, Department of Surgery, Shaheed Suhrawardy Medical College and Hospital, Dhaka

6. Dr. Nur Mohammod Sayed Bin Aziz, Junior Consultant, Department of Surgery, Shaheed Suhrawardy Medical College and Hospital, Dhaka

7. Mohammad Rashedul Hassan, Indoor Medical Officer, Department of Surgery, Shaheed Suhrawardy Medical College and Hospital, Dhaka

Correspondence to: Dr. Nadim Ahmed, Senior Consultant, Dept. of Surgery, Shaheed Suhrawardy Medical College and Hospital, Dhaka. Cell: 01711155052, E-mail: nadimdrdmc@gmail.com

\section{Introduction:}

Enlargement of thyroid gland (goitre) is a common endocrine problem, worldwide. The prevalence of nodular goitre is directly related to the degree of iodine deficiency that is still present in several areas of the world. Sporadically goitre is present in all ecological zones of Bangladesh- plains, hilly areas and flood prone areas. But prevalence of goitre is very much high in Jamalpur, Modhupur and the districts of northwest zones of Bangladesh as these areas showed high rates of iodine deficiency.

Due to illiteracy \& poverty most patients of goitre ignore their enlargement. When the size of goitre is small it creates less problem. But the natural history of goitre continues and the goitre becomes hugely enlarged which is cosmetically very ugly, arise complication of mechanical obstruction like dysponea \&/or dysphagia, acute 
respiratory obstruction. Some becomes extends retrosternally. Secondary thyrotoxicosis occurs in up to $30 \%$ of multinodular goitre (MNG). An increased incidence of cancer reported from endemic areas. Surgery of hugely enlarged goitre or goitre that creates complication is difficult and challenging. In our country only a few number of urban patients come to surgeons with small goitre for cosmetic region. Most patients come to doctor with hugely enlarged goitre or goitre that creates pressure symptoms or complications.

The usual surgical practice in $\mathrm{MNG}$ is subtotal thyroidectomy to conserve sufficient functioning thyroid tissue to subserve normal function \& to salvage parathyroid gland. In many cases the causative factors persist and recurrence is likely. Reoperation for nodular goitre is more difficult and hazardous.

In modern endocrine surgery, total thyroidectomy is preferred for simple MNG, though debate continues. The main advantage of total thyroidectomy is that it offers a radical control over the disease process so that there is a minimal chance of recurrence. Second surgery for recurrent goitre has an increased risk of complication like recurrent laryngeal nerve injury and permanent hypoparathyroidism than the primary thyroid surgery ${ }^{1}$. Avoidance of hazardous second surgery is a reason to prefer total thyroidectomy. Another advantage of total resection of multinodular goitre is that it eliminates an incidental carcinoma found $8.2 \%$ in long standing multinodular goitre otherwise they should need reoperation ${ }^{2}$. Sometimes a posteriorly placed nodule may be felt behind in STT resulting in persistent symptoms of pressure after operation ${ }^{3}$.

The main disadvantage of total thyroidectomy is that it requires immediate and lifelong replacement of thyroxine. But after subtotal resection, it has been customary to give thyroxine to suppress TSH secretion, with the aim of preventing recurrence. Whether this is either necessary or effective is uncertain. Another argument against routine total thyroidectomy for simple multinodular goitre is the fear of increased incidence of complications in total than subtotal thyroidectomy, especially those of hypoparathyroidism and recurrent laryngeal nerve injury. But several studies in specialized centres have shown that total thyroidectomy does not incur more complication than lesser resection procedures provided a reasonable care is taken during surgery.

There is lack of sufficient data on thyroidectomy in our country. The study was conducted to evaluate the intra operative and immediate post operative complications of total and subtotal thyroidectomy for the management of simple multinodular goitre.

\section{Materials and Methods}

The experimental study (Controlled clinical trial) was conducted in the department of Surgery and ENT, Rajshahi Medical College Hospital over a period of 2 years from July 2011 to June 2013. Patients with simple multinodular goitre, undergone total or subtotal thyroidectomy are included in this study. Malignant thyroid diseases, solitary thyroid nodule and recurrence after surgery are excluded from the study. Of the total 83 simple multinodular goitre patients -38 were assigned to total and 45 to subtotal thyroidectomy groups (non random purposive sampling). Preoperative arrangement $\&$ necessary investigation like thyroid function test and other investigation for general anaesthesia were done. A laryngoscopic check of vocal cords was performed for all patients. After completing the necessary procedure for operation the patient was undergone either total or subtotal thyroidectomy. It was decided by the surgeon concern. During postoperative hospital stay (up to 7 days) all patients were followed up with particular attention to hoarseness of voice and signs of hypocalcaemia. Postoperative serum calcium levels were checked on those patients whose clinical manifestation of hypocalcaemia develops. Intraoperative findings (Haemorrhage), early post operative complications (Hypocalcaemia, recurrent laryngeal nerve palsy, haematoma formation, wound complications) and postoperative hospital stay were noted. Using computer software SPSS (Statistical package for Social Sciences) data was processed. Student's t-test was done to analyze the means of quantitative variables such as postoperative hospital stay. \& Chi-square $\left(X^{2}\right)$ and Fisher Exact test was applied to analyze categorical variables.

\section{Result:}

\section{Per-operative blood transfusion:}

Most $(88.9 \%)$ of the patients in subtotal thyroidectomy group and $86.8 \%$ in total thyroidectomy group did not receive any blood transfusion. In subtotal thyroidectomy group 4(8.9\%) patients received 1 unit of blood and $1(2.2 \%)$ patient received 2 units of blood transfusion. In total thyroidectomy group 5(13.2\%) patients received 1 unit of blood transfusion. No significant difference was observed between the two groups regarding per-operative blood transfusion $(\mathrm{p}=0.518)$ (Table I)

Table I

\section{Comparison of per-operative blood transfusion between groups $(n=83)$ :}

\begin{tabular}{|c|c|c|c|}
\hline \multirow[t]{2}{*}{ Units } & \multicolumn{2}{|c|}{ Group } & \multirow[b]{2}{*}{$\begin{array}{c}\mathrm{P}- \\
\text { value }\end{array}$} \\
\hline & $\begin{array}{c}\text { Total } \\
\text { thyroidectomy } \\
(\mathrm{n}=38)\end{array}$ & $\begin{array}{l}\text { Subtotal } \\
\text { thyroidectomy } \\
(n=45)\end{array}$ & \\
\hline 0 & $33(86.8)$ & $40(88.9)$ & \\
\hline 1 & $5(13.2)$ & $4(8.9)$ & 0.518 \\
\hline 2 & 0 & $1(2.2)$ & \\
\hline
\end{tabular}

*Data were analysed using Chi-Square $\left(X^{2}\right)$ test. Figures in the parentheses denoted corresponding percentage. 


\section{Intraoperative haemorrhage:}

One $(2.2 \%)$ patient of STT group had excessive intraoperative haemorrhage that required 2 unit of blood where none of TT group had excessive intraoperative haemorrhage. However, the differences in respect to develop intraoperative haemorrhage between groups did not turn to significant $(\mathrm{p}=0.542$ ) (Table II)

\section{Table II}

Comparison of Intraoperative haemorrhage between groups $(n=83)$ :

\begin{tabular}{lccc}
$\begin{array}{l}\text { Intraoperative } \\
\text { haemorrhage }\end{array}$ & Total & Subtotal & P- \\
& $\begin{array}{c}\text { Group } \\
\text { thyroidectomy } \\
(\mathrm{n}=38)\end{array}$ & $\begin{array}{c}\text { thyroidectomy } \\
(\mathrm{n}=45)\end{array}$ & value \\
\hline Developed & $0(0)$ & $1(2.2)$ & 0.542 \\
Not developed & $38(100)$ & $44(97.8)$ & \\
\hline
\end{tabular}

*Data were analysed using Fisher Exact test. Figures in the parentheses denoted corresponding percentage.

In the present series no case of postoperative haemorrhage (haematoma) was occurred in either group. There was no case of wound infection or wound breakdown.

\section{Recurrent Laryngeal Nerve (RLN) Palsy:}

RLN palsy occurred in $1(2.2 \%)$ patient of STT group while in TT group it was $2(5.3 \%)$. The difference between the groups regarding RLN injury was not statistically significant $(\mathrm{p}=0.459)$ (Table III).

\section{Table III}

Comparison of $R L N$ palsy between groups $(n=83)$ :

\begin{tabular}{lccc} 
RLN Palsy & \multicolumn{2}{c}{ Group } & Total \\
thyroidectomy & $\begin{array}{c}\text { Subtotal } \\
(\mathrm{n}=38)\end{array}$ & $\begin{array}{c}\text { P- } \\
\text { thyroidectomy } \\
(\mathrm{n}=45)\end{array}$ & value \\
\hline Developed & $2(5.3)$ & $1(2.2))$ & 0.459 \\
Not developed & $36(94.7)$ & $44(97.8)$ & \\
\hline
\end{tabular}

*Data were analysed using Chi-Square $\left(X^{2}\right)$ test. Figures in the parentheses denoted corresponding percentage.

\section{Symptomatic hypocalcaemia (Tetany):}

In TT group 3(7.89\%) patients developed tetany whereas in STT group 2(4.44\%) patient developed tetany. There was no significant difference between groups with respect to symptomatic hypocalcaemia developed $(\mathrm{p}=0.510)$ (Figure 1).

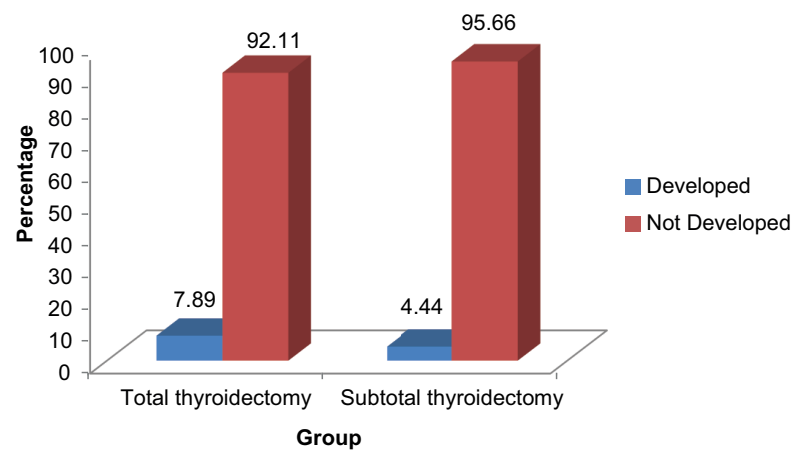

Fig 1: Comparison of development of Tetany between groups $(n=83)$

\section{Total Complications:}

In total thyroidectomy group 5(13.16\%) patients developed complications (3 patients developed tetany $\& 2$ patients developed temporary recurrent nerve palsy) and in subtotal thyroidectomy group $4(8.89 \%)$ patients developed complications ( 2 patients developed tetany \& 1 patient developed temporary recurrent nerve palsy and 1 patient developed intraoperative haemorrhage). There was no significant difference between the groups with respect to total complication developed $(\mathrm{p}=0.533)$ (Figure 2).

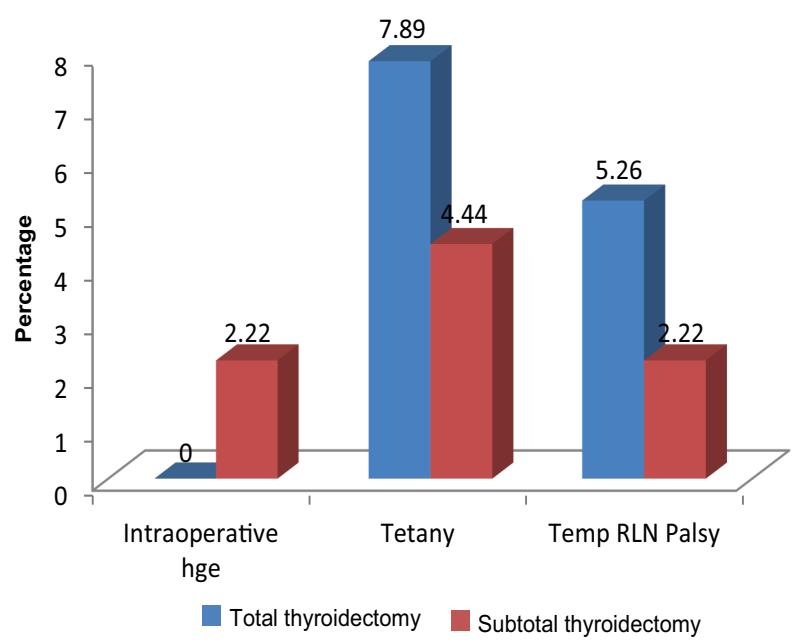

Fig.-2: Comparison of different complication between groups $(n=83)$

\section{Postoperative hospital stay:}

The mean postoperative hospital stay was a bit longer in total thyroidectomy group than that in subtotal thyroidectomy group, although the difference did not reach the level of significance $(6.21 \pm 0.99$ vs. $5.96 \pm 0.79$ days, $\mathrm{p}=0.206$ ) (Table IV). 


\section{Table IV}

\begin{tabular}{lcccc}
$\begin{array}{l}\text { Comparison of postoperative hospital stay between } \\
\text { groups }(n=83)\end{array}$ & N & Mean & SD & p-value \\
Study group & 38 & 6.21 & 0.99 & 0.206 \\
\hline Total thyroidectomy & 45 & 5.96 & 0.79 & \\
Subtotal thyroidectomy & 45 &
\end{tabular}

*Data were analysed using Student's t test

\section{Discussion:}

Extent of thyroidectomy in the management of multinodular goiter is controversial. Although there has been increasing acceptance for performing total thyroidectomy for differentiated thyroid carcinoma, surgeons still continue to debate whether the potential benefits outweigh potential hazards of total thyroidectomy in multinodular goitre. According to some authors total thyroidectomy for multinodular goiter can be useful in adequate eradication of disease, prevention of recurrence, the facilitation of treatment with radioactive iodine and eliminating the risk of malignant change in radiated thyroid glands ${ }^{4}$. Arguments against such a strategy are based on perceived fear of excessive morbidity, particular damage to recurrent laryngeal nerves and parathyroid glands and supplementation of patients with thyroid hormone throughout their life 5 .

Rojdmark reported $42 \%$ recurrence after 30 years follow up in patients who had a subtotal thyroidectomy because of $\mathrm{MNG}^{6}$. Others have reported that recurrence developed in up to $14 \%$ of cases after subtotal thyroidectomy despite drug prophylaxis ${ }^{7}$. Without drug suppressive therapy, the rate of recurrence rises to $43 \%{ }^{8}$. Postoperative L-thyroxine supplementation in patients who had total thyroidectomy can be seen as handicap, but more than half of patients of bilateral subtotal thyroidectomy and Dunhill procedure groups need L-thyroxine supplementation ${ }^{4}$.

A total of 83 patients having simple multinodular goiter were treated by subtotal thyroidectomy ( 45 patients) and total thyroidectomy (38 patients). Then these two methods were compared by means of complications.

In our study 5 (13.2\%) patients in TT group and 4 (8.9\%) patients in STT group needed one unit of blood transfusion $\& 1(2.2 \%)$ patient in STT group needed 2 units of blood transfusion but no significant difference was observed between the two groups ( $\mathrm{p}=0.518$ ). There is no question that haemaostasis is more assured after TT when all vessels have been individually ligated than when dealing with an intact mass of residual vascularised thyroid tissue after STT. Intraoperative bleeding stains tissues and obscures important structures. The risk of other anatomical complications increases with intraoperative bleeding.

One series reported no case of haemotoma ${ }^{9}$ and another reported simple haematoma in $1.4 \%$ of STT group, which resolves spontaneously ${ }^{4}$. In the present series no case of postoperative haemorrhage (haematoma) was occurred in either group. Our findings correlate with the previous study.

Recurrent laryngeal nerve injury in an annoying but avoidable complication of thyroid surgery. There is a popular belief that if you don't disturb the nerve, it will not disturb you. It is a wrong perception to avoid rather than expose the RLN nerve avoids the injury. Deliberate identification of the RLN minimizes the risk of injury.

In a previous series RLN palsy was reported in 3.4\% of all thyroid surgery with incidence of $4.3 \%$ after total and $2 \%$ after subtotal throidectomy ${ }^{10}$. In another series RLN palsy was reports $5.88 \%$ of TT group and $2.85 \%$ after STT group ${ }^{11}$. In present study RLN palsy occurred in $5.3 \%$ of TT group $2.2 \%$ of STT group. However the difference between groups did not turn to significant regarding RLN palsy ( $p=0.459)$. The rate of RLN palsy is consistent with previous published series. They were treated expectantly.

Hypoparathyrodism is another feared complication of thyroid surgery. The parathyroid glands produce parathyroid hormone (PTH), which is intimately involved in regulation of serum calcium. Inadequate production of PTH leads to hypocalcaemia. Manifestation of hypocalcaemia included circumoral numbness, tingling sensation of lips and extremities, positive Trousseaus and Chovstek's sign or frank carpopedal spasm. Hypoparathyrodism, and the resulting hypocalcaemia, any be permanent or transient. The cause of transient hypocalcaemia after surgery is not clearly understood. It may be attributable to temporary hypoparathyrodism caused by reversible ischemia to the parathyroid gland, hypothermia to the glands, or release of endothelin-1.The best way to preserve parathyroid gland function is to identify the glands and to maintain their blood supply.

In a series hypocalcaemia was observed in $11.4 \%$ and 9.5\% of simple MNG undergoing total and subtotal thyroidectomy respectively ${ }^{12}$. In our present study hypocalcaemia was found in $7.89 \%$ of patients of TT group and $4.44 \%$ patients of STT group. No significant difference was observed between the two groups regarding hypocalcaemia $(\mathrm{p}=0.510)$. The rate of hypocalcaemia is almost consistent with previously published results.

Wound related complications are rare in thyroid surgery. Wound infection was reported only in $0.4 \%$ patients of 
TT group and $0.13 \%$ of STT group ${ }^{10}$. In our recent study there was no case of wound infection or wound breakdown.

In a study on comparison of complications between total and subtotal thyroidectomy for the treatment of the patients of simple MNG, no significant difference was found in incidence of RLNs palsy, hypocalcaemia, haemorrhage and wound infection $(\mathrm{p}=0.40,0.65,0.18,0.94$ respectively between TT and STT groups) ${ }^{12}$. Another published study showed in the patients of MNG no significant difference in incidence of haemorrhage, haematoma formation, infection, RLNs palsy, hypocalcemia among total thyroidectomy, bilateral subtotal thyroidectomy and Dunhill procedure $(\mathrm{p}>0.05)^{4}$. In the present study, statistically no significant difference was seen in overall complication rate between total and subtotal thyroidectomy ( $\mathrm{p}=0.533)$.

Two of the published series showed that postoperative hospital stay was statistically similar in different thyroidectomy procedure for the patients of $\mathrm{MNG}^{4,9}$. In our present study mean postoperative stay (6.21 days in TT group and 5.96 days in STT groups) was higher than previous two series. Though mean postoperative stay was longer in TT group than STT group but the difference is not statistically significant $(\mathrm{p}=0.206)$.

It can be concluded that from the present study that the complications of total thyroidectomy is not greater than subtotal thyroidectomy for the patients of simple MNG and this is confirmed by several studies showing that total thyroidectomy can be performed with a morbidity rate comparable to that of lesser procedures. Indeed a well trained endocrine surgeon can achieve the acceptable results with total thyroidectomy provided adequate care is taken for preserving vascularity of parathyroids and for identifying and safe guarding the recurrent laryngeal and external branch of superior laryngeal nerve.

\section{Conclusions:}

Patients of simple multinodular goitre can be operated successfully by either total or subtotal thyroidectomy. Very few patients develop complications like tetany and RLN palsy. There was no significant difference regarding complications between total and subtotal thyroidectomy.

Complications of thyroid surgery did not significantly increase with increasing extent of resection of thyroid gland. With adequate skill and careful surgical techniques total thyroidectomy is a safe procedure as subtotal thyroidectomy.
As the complication of total thyroidectomy is almost similar to subtotal thyroidectomy hence it can be concluded that total thyroidectomy is a better alternative to subtotal thyroidectomy for the treatment of multinodular goitre as total thyroidectomy is useful in adequate eradication of disease, prevention of recurrence, the facilitation of treatment with radioactive iodine and eliminating the risk of malignant change in radiated thyroid glands.

\section{References:}

1. Myint, Tun, Khairuzi G, Hamid A \& Zain M 2003, 'Reoperative Thyroid Surgery in Hospital University Sums Malaysian', Malaysian Journal of Medical Sciences, vol.10,no.1,pp86-89.

2. Giles Y, Boztepe H, Terzioglu and Tezelman S 2004, 'The advantage of total thyroidectomy to avoid reoperation for incidental thyroid cancer in multinodular goitre' Arch Surg., vol.139,no.2,pp179-182

3. Delbridge L, Guinea AL \& Reeve TS 1999, 'Total thyroidectomy for bilateral benign multinodular goitre' Arch Surg, vol.134,pp389-393

4. Koyuncu A, Dokmetas HS, Turan M, Aydin C, Karadayi K, Budent E, Gokgoz S and Sen M, 2003, 'Comparision of different thyroidectomy techniques for benign thyroid disease', Endocrine Journal, vol.50,no.6,pp.723-727

5. Candy B, Sedgwick CE, Meissner WA, Wool MS, Salzman FA and Werber J 1979, 'Risk factor analysis in differentiated thyroid cancer, Cancer, vol.43,pp.810-820

6. Rojdmark J and Jarhult J 1995, 'High long term recurrence rate after subtotal thyroidectomy for nodular goitre', Eur. J. Surg., vol.161, pp.725-7

7. Pappalardo G, Guadalaxara A, Frattaroli FM, Illomei G and Falaschi P 1998, 'Total compared with subtotal thyroidectomy in benign nodular disease' Eur. J. Surg., Vol.164,pp.501-6

8. Piraneo S, Vitri P, Galimberti A, Guzzetti S, Salvaggio A, Bastagli A 1994, 'Recurrence of goitre after operation in euthyroid patients', Eur. J. Surg., vol.160, pp.351-6

9. Ozbas S, Kocak S, Aydintug S, Cakmak A, Demirkiran MA and Wishart GC 2005,'Comparison of the complications of subtotal, near total and total thyroidectomy in surgical management of multinodular goitre', Endocrine Journal, vol.52,no.2, pp.199-250

10. Rosato L, Avenia N, Bernante P, Palma M, Gulino G, Nasi PG, Pelizzo MR and Pezzullo L 2004, 'Complication of thyroid surgery: Analysis of a multicentric study on 14,934 patients operated on in Italy over 5 years', World J. Surg., vol.28,pp.271-276

11. Alimoglu O, Akdag M, Sahin M, Korkut C, Okan I and Kurtulmus N 2005, 'Comparison of surgical techniques for treatment of benign toxic multinodular goitre', World J Surg., vol.29,no.7,pp.921-24

12. Colak T, Akca T, Kanik A, Yapici D and Aydin S 2004, 'Total versus subtotal thyroidectomy for the management of benign multinodular goitre in an endemic region', ANZ J. Surg., vol.74,pp.974-978. 